\title{
Expression of ErbB receptors in the pre-pubertal and pubertal virgin mammary glands of dairy cows
}

\author{
Byung-Woo Lee ${ }^{1}$, Yo-Han Kim ${ }^{1}$, Byung-Suk Jeon ${ }^{1}$, Naresh Kumar Singh ${ }^{2}$, Won-Ho Kim ${ }^{3}$, \\ Meing-Jooung Kim ${ }^{4}$, Byung-II Yoon ${ }^{1, *}$ \\ Colleges of ${ }^{1}$ Veterinary Medicine, and ${ }^{2}$ Animal Life Science, Kangwon National University, Chuncheon 200-701, Korea \\ ${ }^{3}$ Jeonnam Livestock Research Institute, Gangiin 527-822, Korea \\ ${ }^{4}$ National Institute of Animal Science, Cheonan 330-801, Korea
}

(Received: November 16, 2012; Revised: November 21, 2012; Accepted: November 26, 2012)

\begin{abstract}
In the present study, we investigated the expression patterns of ErbB family proteins in the pre-pubertal and pubertal mammary glands of dairy cows in association with gland development. For this study, we performed immunohistochemistry for ErbB-1-4 and Ki-67 cell proliferation marker. We found that the pre-pubertal and pubertal mammary glands had typical structures, including ducts and terminal end buds embedded in the stroma, and no development of lobuloalveolar structures. On immunohistochemistry, ErbB-2 and ErbB-3 were strongly expressed in the cytoplasm and nuclei in the epithelial cells of mammary ducts and terminal end buds, and stromal cells, whereas ErbB-1 and ErbB-4 were weakly expressed only in the cytoplasm of gland epithelium and stromal cells, irrespective of the developmental stage. Cell proliferation was inactive in the mammary gland cell compartments in both phases. Thus, expression of the ErbB family in the developing mammary glands was not associated with their functional effects, such as cell proliferation and lobuloalveolar development. In conclusion, ErbB receptors were differentially expressed in the epithelial and stromal cells of virgin mammary glands of dairy cows. Compared with rodent mammary glands, ErbB-3 and ErbB-4 were found to be highly expressed in bovine mammary glands.
\end{abstract}

Keywords : dairy cow, ErbB receptors, immunohistochemistry, mammary gland

\section{Introduction}

Mammary gland morphogenesis is a panoramic and orchestrated process involving hormones, growth factors, growth factor tyrosine kinase receptors, and extracellular matrix molecules and proteases [12]. For mammary gland development, the cell populations comprising the mammary gland, including epithelial cells, stromal cells and mesenchymal fat cells, cooperate with dynamic expression patterns of those regulating factors [19]. However, the integrated mechanism of mammary gland morphogenesis remains incompletely understood.

The ErbB family of receptor tyrosine kinases is important in the regulation of cell growth and differentiation in mammary glands [19]. The ErbB signaling system is composed of four homologous receptors, ErbB-1 4, and their ligands, the binding of which triggers signaling for mammary epithelium growth [9]. Epidermal growth factor (EGF) tyrosine kinase receptors are integral proteins in the cell membrane. They form homodimers or heterodimers in various combinations in response to their ligands, such as EGF, transforming growth factor-alpha, amphiregulin, heparin-binding EGF, betacellulin, epiregulin, and neuregulins (NRG) [9, 22].

The expression of the ErbB family differs dynamically in each cell population during mammary gland development. In studies using mice, ErbB-1 and ErbB-2 were differentially expressed in the epithelial cells, stromal cells and mesenchymal fat cells of developing mammary glands at the protein level, whereas ErbB-3 and ErbB-4 were not detectable in virgin mammary glands [19]. Interestingly, in addition to ErbB1 and ErbB-2, ErbB-3 and ErbB-4 are highly expressed in the epithelial cells of the mammary gland throughout pregnancy and during lactation [19]. Co-localization of these receptors in cell populations is likely to be closely associated with their working mechanisms, which lead to the formation of homodimers or heterodimers at all stages of mammary gland development. The ability of ErbB receptors to form homodimers and heterodimers in various combinations is dependent on which ligand is involved [6]. EGF and EGFlike ligands can preferentially induce heterodimerization of ErbB-1 and ErbB-2, whereas NRGs stimulate formation of heterodimers of ErbB-2 with either ErbB-3 or ErbB-4 [3]. In

*Corresponding author

Tel: +82-33-250-8679, Fax: +82-33-244-2367

E-mail: byoon@kangwon.ac.kr 
developing virgin mammary glands of mice, ErbB-1 and ErbB-2 are distinctly expressed in epithelial cells and surrounding stromal cells and fat cells, suggesting that they may play a major role among the ErbB receptors in the developmental stages of the mammary gland before pregnancy [19]. In contrast to ErbB-1 and ErbB-2, which are expressed throughout puberty, pregnancy, lactation, and involution, ErbB-3 and ErbB-4 are notably expressed only during late pregnancy and lactation, suggesting active roles in the mammary glands at these stages [19].

The expression patterns of ErbB receptors have been shown to differ considerably among species. For instance, unlike in mice, ErbB-4 is strongly expressed in the pubescent mammary glands of rats [5].

Mammary morphogenesis has been studied in laboratory animals, but never in dairy cows. In the present study, we investigated the expression patterns of ErbB family proteins in the immature and mature virgin mammary glands of dairy cows. The dairy industry has long been interested in finding ways to increase the quantity of milk produced during the life of a dairy cow. Our study will provide useful information toward this goal.

\section{Materials and Methods}

\section{Animals and biopsy of the mammary gland}

For this study, ten Holstein dairy cattle born between August and November 2010 were selected randomly. The cows were biopsied at about 8 and 13 months of age to represent pre-pubertal and pubertal stages, respectively. The animals were sedated mildly via intramuscular injection of xylazine hydrochloride (Bayer Korea, Korea); $46.6 \mathrm{mg} / \mathrm{head}$ for pre-pubertal cows and $69.9 \mathrm{mg} /$ head for pubertal cows, respectively. The midsection of left or right rear quarter was selected for the biopsy site. Prior to biopsy, the biopsy site was disinfected with $70 \%$ alcohol and povidone-iodine, and a small skin incision was made at the entry site of the biopsy instrument (4 mm diameter and $100 \mathrm{~mm}$ length; Somatex Medical Technologies GmbH, Germany). A sterilized biopsy instrument was used to collect a sample of mammary gland tissue. Following biopsy, antibiotic powder, negasunt (Bayer Korea) was applied to the wound, and the animals were given antibiotics, cefazolin sodium $(2,500 \mathrm{mg} / \mathrm{head}$; Eaglevet, Korea) by intramuscular injection. The mammary gland specimens were immediately fixed in $10 \%$ neutral buffered formalin solution.

\section{Histology and immunohistochemistry for ERBB fam- ily proteins}

The mammary gland tissues in formalin fixative were processed routinely for paraffin embedding and sectioned into 3 5- $\mu \mathrm{m}$ specimens, followed by hematoxylin and eosin staining or immunohistochemistry, respectively. Histological examination was performed under a light microscope. For immunohistochemistry, the antigens were retrieved by heat- ing them in citrate buffer ( $\mathrm{pH}$ 6.0). Endogenous peroxidase activity was eliminated by treating the sections in a solution of $3 \%$ hydrogen peroxide in methanol for $30 \mathrm{~min}$ at room temperature. After blocking of nonspecific binding sites with normal goat serum for $1 \mathrm{~h}$ at room temperature, the sections were incubated overnight at $4^{\circ} \mathrm{C}$ with the appropriately diluted primary antibodies for ErbB-1 (1:500), ErbB-2 (1 : $1,000)$, ErbB-3 (1:500), ErbB-4 (1:250), and Ki-67 (1: 200), respectively. The primary antibodies of ErbB-1 4 were purchased from Santa Cruz Biotechnology (USA); they were all rabbit-polyclonal affinity-purified antibodies generated against a peptide map at the C-terminus of human-origin ErbBs. Ki-67 antibody (Acris Antibiotics, Germany) was created using a synthetic peptide from the C-terminus of human Ki-67, and diluted to $1: 200$ for immunohistochemical analysis. After washing in phosphate-buffered saline, the tissue sections were incubated with anti-rabbit immunoglobulin $G$ secondary antibodies conjugated with biotin for $1 \mathrm{~h}$ at room temperature, followed by incubation with avidin-biotin complex reagent for $30 \mathrm{~min}$ at room temperature. 3,3'-Diaminobenzidine solution was used as a chromogen substrate. Sections were counterstained with modified Mayer's hematoxylin for $3 \mathrm{~min}$. To determine the Ki-67 labeling index, 350 520 glandular epithelial cells were counted, and the percentage of Ki-67 nuclear-positive cells was calculated.

\section{Results}

\section{Histological characterization of developing mammary glands of dairy cows}

On histology, the mammary glands of dairy cows had typical structures, including parenchymal compartments without lobuloalveolar structures as well as a mesenchymal compartment (Fig. 1). The parenchymal compartments were composed of ducts and terminal end buds (TEBs) embedded in stroma, including connective tissue and fat pads (Fig. 1). The ducts or ductules consisted of simple columnar or cuboidal epithelial cells. Flat myoepithelial cells surrounding the luminal epithelium separated the parenchymal and mesenchymal compartments of the glands (Fig. 1). TEBs, the major sites of cell proliferation, had stratified cuboidal epithelium

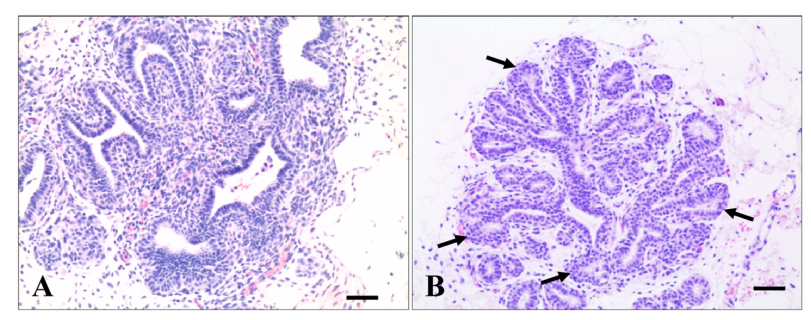

Fig. 1. Histological features of pre-pubertal (A) and pubertal mammary glands (B) of dairy cow. Note the mammary ducts composed of simple columnar or cuboidal epithelia, surrounded by stromal compartments. More terminal end buds (arrows) were observed in the pubertal mammary glands (B). H\&E Stain, Scale $\operatorname{Bar}=50 \mu \mathrm{m}$. 
Table 1. Immunoreactivity and location of ErbB family proteins in the cell components of mammary glands of dairy cow

\begin{tabular}{|c|c|c|c|c|c|c|c|}
\hline \multicolumn{2}{|c|}{ Cell population } & \multicolumn{2}{|c|}{ Ductal epithelium } & \multicolumn{2}{|c|}{ TEBs } & \multicolumn{2}{|c|}{ Stroma } \\
\hline Stage & ErbBs & cytoplasm & nucleus & cytoplasm & nucleus & cytoplasm & nucleus \\
\hline \multirow{4}{*}{ Pre-puberty } & ErbB-1 & $2+$ & - & $2+$ & - & $2+$ & - \\
\hline & ErbB-2 & $4+$ & $4+$ & $3+$ & $4+$ & $2+$ & $3+$ \\
\hline & ErbB-3 & $3+$ & $4+$ & $4+$ & $4+$ & $2+$ & $4+$ \\
\hline & ErbB-4 & $2+$ & - & $2+$ & - & $2+$ & - \\
\hline \multirow{4}{*}{ Puberty } & ErbB-1 & $1+$ & - & $1+$ & - & $1+$ & - \\
\hline & ErbB-2 & $4+$ & $4+$ & $4+$ & $4+$ & $2+$ & $3+$ \\
\hline & ErbB-3 & $4+$ & $4+$ & $4+$ & $4+$ & $3+$ & $3+$ \\
\hline & ErbB-4 & $2+$ & - & $2+$ & - & $1+$ & - \\
\hline
\end{tabular}

TEBs: terminal end buds. -: negative, 1+: weak, 2+: mild, 3+: moderate, 4+: strong.

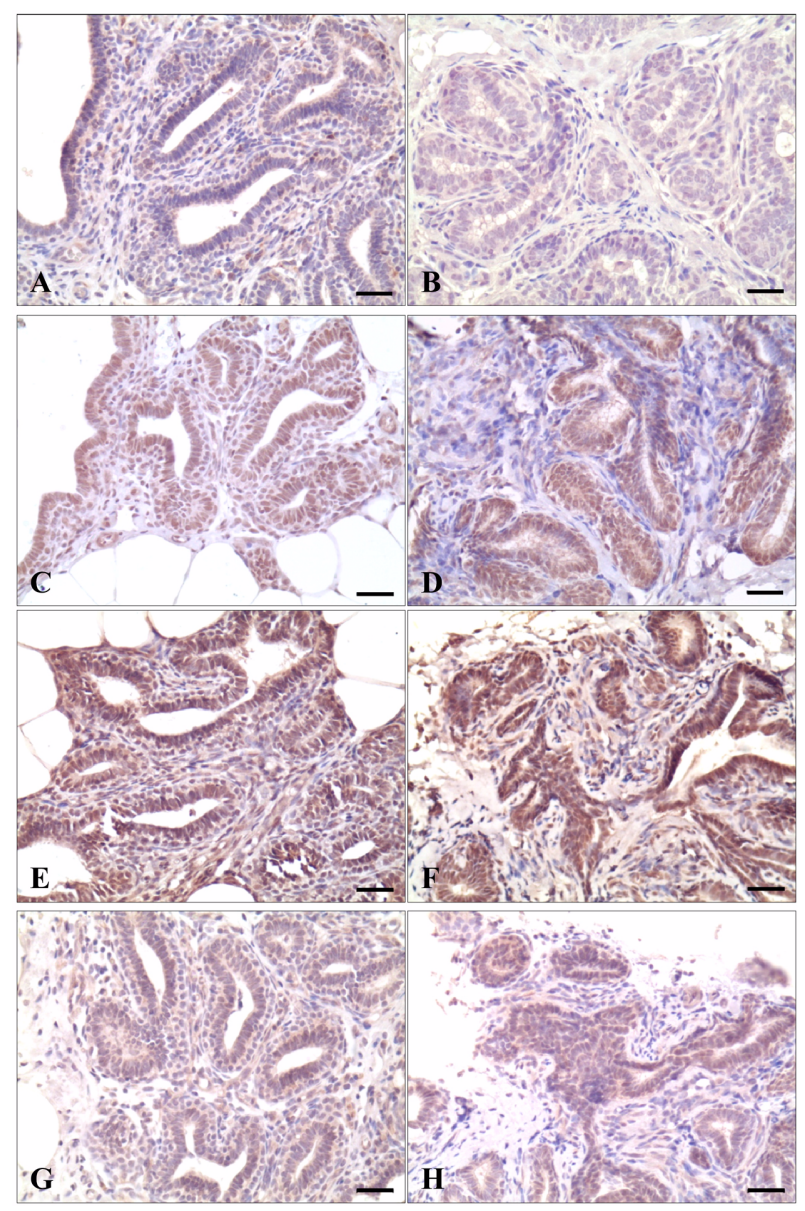

Fig. 2. Immunohistochemistry of pre-pubertal (A, C, E, and G) and pubertal mammary glands $(\mathrm{B}, \mathrm{D}, \mathrm{F}$, and $\mathrm{H})$ for ErbB-1 (A and B), ErbB-2 (C and D), ErbB-3 (E and F), and ErbB-4 (G and $\mathrm{H})$. The ErbB family proteins were differentially expressed in either cytoplasm or neclei or both. ErbB2 and ErbB3 were all highly expressed in the epithelial and stromal cells of prepubertal and pubertal mammary glands, while expression of ErbB-1 and ErbB-4 were relatively weak in the developing mammary glands. ABC method, Scale Bar $=30 \mu \mathrm{m}$.

called body cells and a single myoepithelial layer, termed cap cells (Fig. 1). More TEBs were observed in pubertal mam-

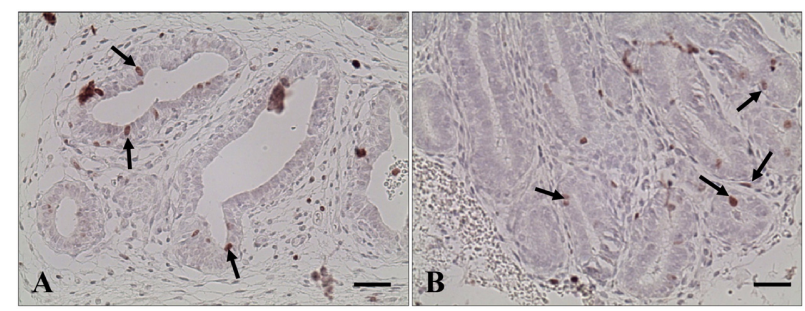

Fig. 3. Immunostaining of $\mathrm{Ki}-67$ in the pre-pubertal (A) and pubertal mammary glands (B) of dairy cow. Only few ductal epithelial cells were positive for cell proliferation marker in both pre-pubertal and pubertal mammary glands (arrows). ABC method, Scale Bar $=30 \mu \mathrm{m}$.

mary glands with narrower lumens than in pre-pubertal glands (Fig. 1).

Comparative immunoreactivity for ErbB family proteins and $\mathrm{Ki}-67$ in the developing mammary glands of the dairy cow

In the mammary glands of pre-pubertal dairy cows, ErbB receptors were differentially expressed in the cytoplasm and nuclei of epithelial and stromal cells (Table 1, Fig. 2). ErbB-2 and ErbB-3 were strongly expressed in both cytoplasm and nuclei in the epithelial cells of mammary ducts and TEBs, whereas ErbB-1 and ErbB-4 were weakly expressed only in cytoplasm of gland epithelium (Table 1, Fig. 2). This differential expression pattern of ErbB receptors in the stromal cells was similar to that of the glandular epithelial cells, except that expression of ErbB-2 and ErbB-4 was comparatively weak; ErbB-2 and ErbB-4 proteins were localized in both the cytoplasm and nuclei, but immunoreactivity of ErbB-1 and ErbB-4 was evident only in the cytoplasm (Table 1, Fig. 2).

The expression of ErbB receptors in pubertal mammary glands did not differ markedly from that in pre-pubertal mammary glands, but the immunoreactivity of ErbB-1 was weaker in the cytoplasm of gland epithelial cells (Table 1, Fig. 2). Those patterns of immunoreactivity for ErbB receptors were consistent in all the examined animals without individual variation. 
The mammary gland cell compartments had minimal cell proliferation in the pre-pubertal and pubertal phases, as evidenced by the low Ki-67 labeling index (Fig. 3). Few glandular epithelial cells were positive for Ki-67 in the developing mammary glands (Fig. 3). The Ki-67 labeling index of the mammary glands ranged from $0 \sim 4.05 \%$ and $0 \sim 4.8 \%$ in the pre-pubertal and pubertal glands, respectively.

\section{Discussion}

In dairy cows, cell division is directly correlated with milk yield postpartum [10]. Although the molecular events associated with mammary gland development are complex and not well established in dairy cows, ErbB receptor signaling may play an important role, as in rodents [20, 21, 23]. The present study assessed the expression of the ErbB family in the developing mammary glands of dairy cows. Although the expression and function of ErbB receptors have been described in rodents, to our knowledge, this study provides the first evidence of ErbB family expression in dairy cow mammary gland development.

The present study demonstrated that expression of the ErbB family in the mammary glands of dairy cows differs from that in rodents. Previous reports have shown that ErbB1 and ErbB-2 are expressed before pregnancy for ductal morphogenesis in rodent mammary glands, and ErbB-3 and ErbB-4 are responsible for ductal morphogenesis and differentiation of mammary epithelial cells, respectively, thereafter $[7,8,14,19,26]$. Increased expression of ErbB-3 and ErbB-4 prior to the first pregnancy is the most notable difference between the mammary glands of dairy cows and rodents, which was first evidenced by the present study. In rodents, ErbB-3 and ErbB-4 proteins were undetectable in virgin mammary glands, but highly expressed in the glands of pregnant and lactating animals [19]. Based on the rodent studies, ErbB-3 and ErbB-4 seem to play a role in the differentiation of mammary gland cells into lactating glands [19]. The present study did not determine why ErbB-3 and ErbB-4 are, unlike in rodents, highly expressed in the virgin mammary glands of dairy cows.

Another difference between the mammary glands of dairy cows and rodents is a relatively low expression of ErbB-1. In rodent mammary glands, ErbB-1 and ErbB-2 are expressed concurrently before and after pregnancy [19]. They are highly expressed in mature virgin and pregnant mammary glands in rodents. In the present study, ErbB-2 was very strongly expressed in the epithelial cells of pre-pubertal and pubertal mammary glands, which was consistent with the results in the rodent [19]. However, low expression of ErbB1 in the virgin mammary glands of dairy cows differed from the expression in rodents, which was increased in virgin mature mammary glands before pregnancy.

The increased expression of ErbB-2, ErbB-3, and ErbB-4 was not likely associated with cell proliferation in mammary glands in the present study, as only a few Ki-67-positive pro- liferating cells were evident in the pre-pubertal and pubertal mammary glands in which the ErbB receptors were strongly expressed. In addition, lobuloalveolar development, triggered by ErbB-3 and ErbB-4, was poor, although the ErbB receptors were highly expressed in the present study. These results suggest that the highly expressed ErbB family proteins were not actively promoting cell proliferation in the examined phases of mammary gland development. The ligands of ErbB receptors are required to phosphorylate the receptors for functional activation. Following binding of ErbB ligands, ErbB receptors homodimerize or heterodimerize with the same or additional ErbB receptors, after which the binding complex is phosphorylated upon receptor activation, recruiting the phosphopeptide binding adaptors and signaling proteins $[16,17,27]$. Ligand-ErbB binding for the growth of mammary glands was shown to be regulated by estradiol and progesterone, which stimulate the paracrine secretion of ErbB ligands by mammary gland cells [11, 13, 20]. Thus, the low proliferation of the glandular epithelial cells despite increased expression of ErbB receptors may be associated with low levels of ovarian hormones, although our hypothesis should be further investigated in future studies [4]. The close relationship between hormone level and paracrine secretion of ErbB ligands was also evident in the mammary glands during pregnancy $[1,18,25]$.

Another interesting finding is that ErbB-2 and ErbB-3 are co-localized in the nuclei of mammary epithelial cells, as well as in the cytoplasm. Nuclear expression of ErbB proteins has often been reported in human mammary glands and cancer cells, including breast cancers. However, the significance of the nuclear expression of ErbB receptors in virgin mammary glands observed in the present study remains unclear [2, 15, 24].

In summary, ErbB receptors were differentially expressed in the epithelial and stromal cells of virgin mammary glands of dairy cows. Unlike in rodent mammary glands, ErbB-3 and ErbB-4 were highly expressed in the mammary glandular and stromal cells, but this expression was not associated with cell proliferation or lobuloalveolar development.

\section{Acknowledgments}

This work was carried out with the support of "Cooperative Research Program for Agriculture Science \& Technology Development (Project No. PJ9071392012)" Rural Development Administration, Republic of Korea. Authors also thank the farmers, Mr. Young-Soo $\mathrm{Na}$ and Mr. Gab-Jae Kim, for their kind cooperation for this study.

\section{References}

1. Anderson E. The role of oestrogen and progesterone receptors in human mammary development and tumorigenesis. Breast Cancer Res 2002, 4, 197-201.

2. Anido J, Scaltriti M, Bech Serra JJ, Santiago Josefat B, Todo FR, Baselga J, Arribas J. Biosynthesis of tumorigenic 
HER2 C-terminal fragments by alternative initiation of translation. EMBO J 2006, 25, 3234-3244.

3. Chen X, Levkowitz G, Tzahar E, Karunagaran D, Lavi S, Ben-Baruch N, Leitner O, Ratzkin BJ, Bacus SS, Yarden Y. An immunological approach reveals biological differences between the two NDF/heregulin receptors, ErbB3 and ErbB-4. J Biol Chem 1996, 271, 7620-7629.

4. Convey EM. Serum hormone concentrations in ruminants during mammary growth, lactogenesis, and lactation: a review. J Dairy Sci 1974, 57, 905-917.

5. Darcy KM, Zangani D, Wohlhueter AL, Huang RY, Vaughan MM, Russell JA, Ip MM. Changes in ErbB2 (her-2/neu), ErbB3, and ErbB4 during growth, differentiation, and apoptosis of normal rat mammary epithelial cells. $\mathrm{J}$ Histochem Cytochem 2000, 48, 63-80.

6. Heldin CH. Dimerization of cell surface receptors in signal transduction. Cell 1995, 80, 213-223.

7. Jackson-Fisher AJ, Bellinger G, Breindel JL, Tavassoli FA, Booth CJ, Duong JK, Stern DF. ErbB3 is required for ductal morphogenesis in the mouse mammary gland. Breast Cancer Res 2008, 10, R96.

8. Jackson-Fisher AJ, Bellinger G, Ramabhadran R, Morris JK, Lee KF, Stern DF. ErbB2 is required for ductal morphogenesis of the mammary gland. Proc Natl Acad Sci U S A 2004, 101, 17138-17143.

9. Jorissen RN, Walker F, Pouliot N, Garrett TP, Ward CW, Burgess AW. Epidermal growth factor receptor: mechanisms of activation and signalling. Exp Cell Res 2003, 284, 31-53.

10. Knight CH. The importance of cell division in udder development and lactation. Livest Prod Sci 2000, 66, 169176.

11. Mallepell S, Krust A, Chambon P, Brisken C. Paracrine signaling through the epithelial estrogen receptor alpha is required for proliferation and morphogenesis in the mammary gland. Proc Natl Acad Sci U S A 2006, 103, 2196-2201.

12. McNally S, Martin F. Molecular regulators of pubertal mammary gland development. Ann Med 2011, 43, 212-234.

13. Mukku VR, Stancel GM. Regulation of epidermal growth factor receptor by estrogen. J Biol Chem 1985, 260, 98209824.

14. Muraoka-Cook RS, Feng SM, Strunk KE, Earp HS 3rd. ErbB4/HER4: role in mammary gland development, differentiation and growth inhibition. J Mammary Gland Biol Neoplasia 2008, 13, 235-246.

15. Offterdinger M, Schöfer C, Weipoltshammer K, Grunt
TW. c-erbB-3: a nuclear protein in mammary epithelial cells. J Cell Biol 2002, 157, 929-939.

16. Olayioye MA, Neve RM, Lane HA, Hynes NE. The ErbB signaling network: receptor heterodimerization in development and cancer. EMBO J 2000, 19, 3159-3167.

17. Riese DJ 2nd, Stern DF. Specificity within the EGF family/ErbB receptor family signaling network. Bioessays 1998, 20, 41-48.

18. Schams D, Kohlenberg S, Amselgruber W, Berisha B, Pfaffl MW, Sinowatz F. Expression and localisation of oestrogen and progesterone receptors in the bovine mammary gland during development, function and involution. $\mathrm{J}$ Endocrinol 2003, 177, 305-317.

19. Schroeder JA, Lee DC. Dynamic expression and activation of ERBB receptors in the developing mouse mammary gland. Cell Growth Differ 1998, 9, 451-464.

20. Sheffield LG. Hormonal regulation of epidermal growth factor receptor content and signaling in bovine mammary tissue. Endocrinology 1998, 139, 4568-4575.

21. Spitzer E, Grosse R. EGF receptors on plasma membranes purified from bovine mammary gland of lactating and pregnant animals. Biochem Int 1987, 14, 581-588.

22. Stern DF. ErbBs in mammary development. Exp Cell Res 2003, 284, 89-98.

23. Sternlicht MD, Sunnarborg SW, Kouros-Mehr H, Yu Y, Lee DC, Werb Z. Mammary ductal morphogenesis requires paracrine activation of stromal EGFR via ADAM17dependent shedding of epithelial amphiregulin. Development 2005, 132, 3923-3933.

24. Wang SC, Lien HC, Xia W, Chen IF, Lo HW, Wang Z, Ali-Seyed M, Lee DF, Bartholomeusz G, Ou-Yang F, Giri DK, Hung MC. Binding at and transactivation of the COX-2 promoter by nuclear tyrosine kinase receptor ErbB2. Cancer Cell 2004, 6, 251-261.

25. Welsch CW, McManus MJ, DeHoog JV, Goodman GT, Tucker HA. Hormone-induced growth and lactogensis of grafts of bovine mammary gland maintained in the athymic "nude" mouse. Cancer Res 1979, 39 (6 Pt 1), 2046-2050.

26. Xie W, Paterson AJ, Chin E, Nabell LM, Kudlow JE. Targeted expression of a dominant negative epidermal growth factor receptor in the mammary gland of transgenic mice inhibits pubertal mammary duct development. Mol Endocrinol 1997, 11, 1766-1781.

27. Yarden Y, Sliwkowski MX. Untangling the ErbB signalling network. Nat Rev Mol Cell Biol 2001, 2, 127-137. 